\title{
Design and Realization of the Automatic Gear Machining System
}

\author{
Hui Qian ${ }^{1, a}$, Nanyan Shen ${ }^{1, b^{*}}$, Ran Ju ${ }^{1, c}$ and Liang Tong ${ }^{1, d}$ \\ ${ }^{1}$ School of Mechatronic Engineering and Automation, Shanghai Key Laboratory of Intelligent \\ Manufacturing and Robotics, Shanghai University, Shanghai 200072, China \\ aqianz@shu.edu.cn, bshny@shu.edu.cn, ${ }^{\mathrm{a}}$ RanJush@163.com, ${ }^{\mathrm{d}}$ tongl@shu.edu.cn
}

Keywords: Feeding and unloading Robot, facility layout simulation, evaluation index, gear machining Abstract. Being widely used in modern machinery and equipment, gears drive functions in transmitting motion and power at a specified gear ratio. Based on the general application of NC machining technology, it is increasingly important to realize the automatic production from the gear blanks to the finished gears for the high productivity and the stable product quality. Therefore the feeding and unloading robot is required to realize the material handling among the CNC machine tools for each process. According to the analysis of the typical processing technology and equipment of gears, the facility layout is designed and the productive tempo is calculated by using the simulation software ROBOGUIDE. And the comprehensive evaluation index is introduced to find out the better facility layout accordin to the given requirements. The automatic gear machining system is on exhibition in Shanghai-FANUC Robotics CO.,Ltd.

\section{Introduction}

With the constant advancement on robot technology and the fast development of robot industry domestic and abroad, industrial robot makes a big sense to automatic production line, becoming the key point of intelligent manufacturing and industrial automation, and is also an indispensable part of CNC machine tools automation[1]. In recent years there has been many achievements in research on industrial robot and automatic processing system. Jeon, Jae Wook; Ha,Young youl have made studies on their acceleration and deceleration[2], Hu Fuwen on the team work of pneumatic manipulator and CNC machine[3] and Li Rongli on robot control system of feeding and unloading based on PLC[4].

Facility layout refers to arranging, according to certain principles, the units, working ground and production facility under the constraints of equipment and workshop space, so as to create an optimal production relation and minimize the cost of material delivery[5]. Drira A has studied on facility layout problems[6]. Liu Shu has studied on facility planning in production logistics system[7]; Kang Liutao has studied the layout simulation and logistics optimization in digital factory[8].

Based on the analysis of the typical processing technology and the given technology requirements, the studies are conducted to design the facility layout and to calculate the productive tempo. And the comprehensive evaluation index is introduced to obtain the better layout plan.

\section{Analysis on Processing Technology of Gear}

The processing case discussed in this passage is about one single type of cylindrical gear whose drawing is shown in Fig. 1. The gear requires a 7 degree of accuracy and the conventional gear hobbing can meet its requirement. 


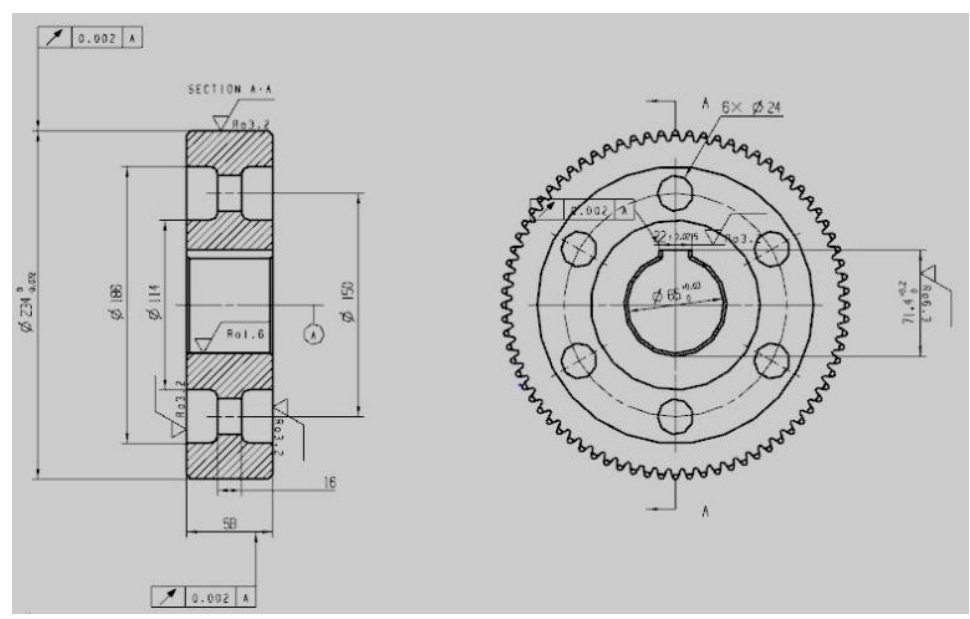

Fig. $12 \mathrm{D}$ engineering drawing of machined gear

On automated production, we must ascertain first the technology of parts processing and meet the requirement of production accuracy, next we need to find out the rhythm of processing to ensure productivity. In this passage, we put forward a need to ascertain the choice of gear processing technology as well as the rhythm coordination between loaded robot and machine tool during automated production.

The gear automated production line that this passage studies uses the processing technology from hobbing, chamfering to shaving.

The paper talks about a batch production line of a single product, which satisfies the demand of the production rhythm In practical production, the whole process starts from grabbing gear blanks by robot to hobbing, chamfering and shaving. To satisfy the demand of production accuracy in automated production, a detector is needed after the processing to examine the finished gears, achieving the online automated cutter-offset to ensure the environment is clean during processing, one oil thrower is needed between hobbing and chamfering, and another is added between chamfering and shaving. Thus the posts as above are needed in the later research to optimize integral processing time, reduce rhythm time and improve productivity. Thus the detector and oil thrower are needed in the later research to optimize integral processing time, reduce tempo time and improve productivity.

\section{Design and Simulation of Gear Automatic Processing Line}

The layout of gear automatic processing line is shown in Fig. 2. To choose the optimal layout plan various factors are considered under the given comprehensive evaluation index, including the time spent and equipment condition in hobbing, chamfering and shaving, the floor space of all facilities and the conditions of foot paths and pit lanes, as well as the logistics tempo and cost of the whole line. As the processing mode of gears is is producing a single kind of gear massively .Common production line layouts include linear layout, U-shaped layout, annular layout and island-shaped layout. And the optimal layout plan will be chosen from them after analysis. 


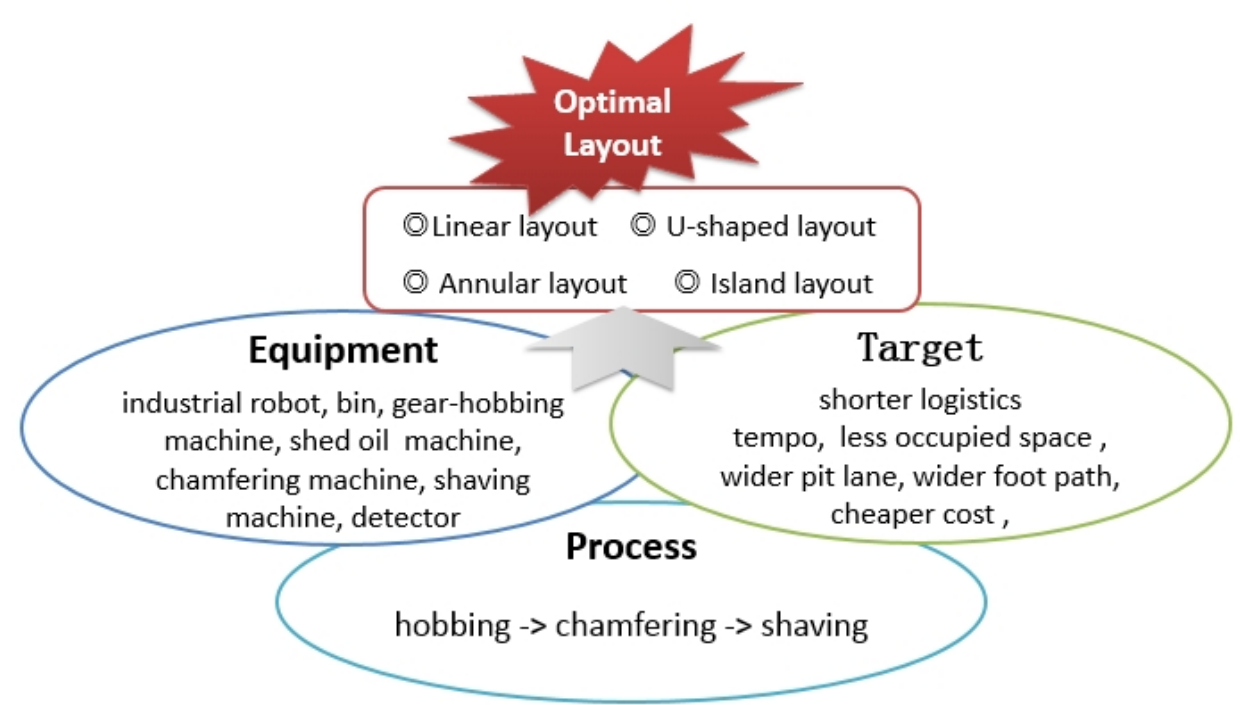

Fig. 2 Optimal layout problem of automatic production line of gear

All objectives pursued by the layout design of gear automatic processing line and the concrete statistics are shown in Table 1.

Table 1 Layout objective of production line

\begin{tabular}{|c|c|}
\hline Single object & Value \\
\hline logistics tempo $A_{1}{ }^{*}\left[\mathrm{~m}^{2}\right]$ & $\leq 100$ \\
\hline occupied space $A_{2}{ }^{*}[\mathrm{~s}]$ & $\leq 110$ \\
\hline pit lane $A_{3}{ }^{*}[\mathrm{~m}]$ & $\geq 1.00$ \\
\hline foot path $A_{4}{ }^{*}[\mathrm{~m}]$ & $\geq 0.45$ \\
\hline $\operatorname{cost} A_{5}{ }^{*}[¥]$ & $\leq 450000$ \\
\hline
\end{tabular}

The need of stations for automatic robotic logistics during hobbing, chamfering and shaving and the flow of these procedures are shown in Table 2.

Table 2 Automatic machine processes of gear

\begin{tabular}{|c|c|}
\hline Number & Processes \\
\hline 1 & Robots take the gear to the hobbing machine from loading \\
\hline 2 & $\begin{array}{r}\text { Robots enter the hobbing machine, take out the work in it, putting it into the oil } \\
\text { thrower and then load new works to the hobbing machine }\end{array}$ \\
\hline 3 & $\begin{array}{r}\text { Robots take the work in the hobbing machine to the chamfering machine, grab out the } \\
\text { finished works in it and add some new works to thechamfering machine }\end{array}$ \\
\hline 4 & $\begin{array}{r}\text { Robots move to the shaving machine, take out the finished works in it, putting them } \\
\text { into the oil thrower and load new works to the shaving machine }\end{array}$ \\
\hline 5 & Robots grab works from the oil thrower, load them to the detector to examine the size \\
\hline 6 & Robots unload the works to the unloading bin \\
\hline 7 & Robots go back to the initial point \\
\hline
\end{tabular}

In the later layout and rhythm simulation, logistics and rhythm simulation will be proceeded in accordance with the procedures in the table.

3D Model Building of the Gear Processing System. Through previous studies we have ascertained the machine tool and relevant accessory equipment demanded during the whole processing, 
and what comes next is 3D modeling and simulation of relevant equipment. And Roboguide of FANUC Company is used in this paper as the simulation environment software.

The 3D system modeling in this paper does not show all details of the machine tool, for 3D model here is only used for layout reference rather than actual processing reference. Thus the prime principle of building the model is to set a specific and accurate model parameter related with the layout( the machine tool, length, width and height of facility, the interference environment to be considered during robot feeding and unloading, feeding and unloading place). After considering live interference, there is no need to model specifically the inner environment of every machine tool and facility. And the modeling of machine tool cabin door is necessary because its switch time has an influence on the integral tempo. The 3D figure of chamfering machine is an example. Fig. 3 shows the modeling for the body of chamfering machine and Fig. 4 shows the modeling for its door.

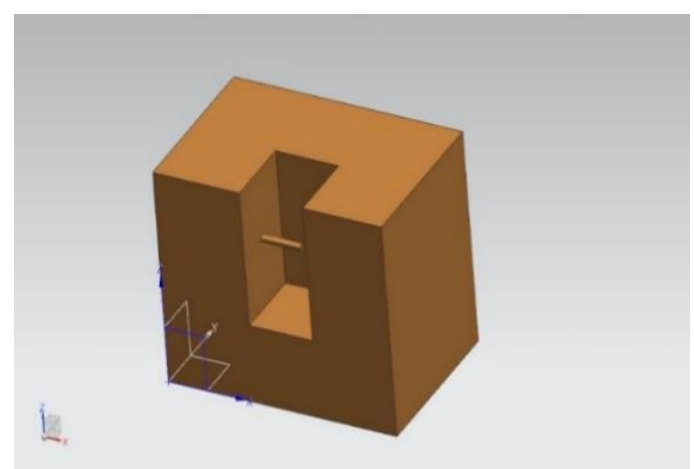

Fig. 3 modeling of the chamfering machine

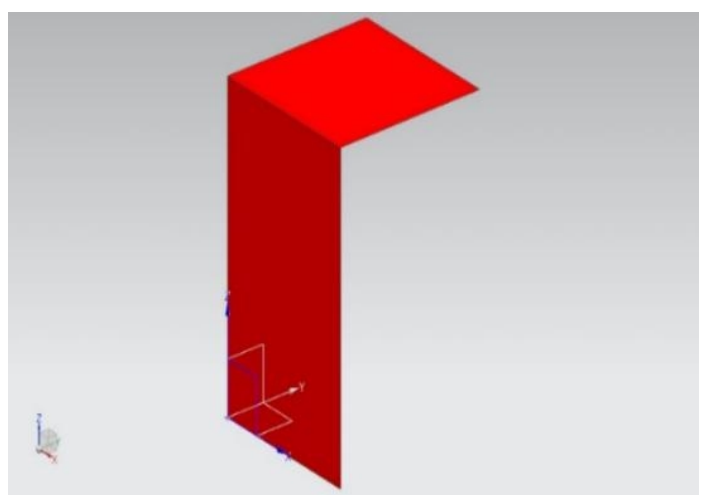

Fig. 4 modeling of the cabin door of the chamfering machine

Apart from the conventional machine tool modeling, this paper studies the modeling of robot paw. During the whole process, robots serve as a carrier of materials through workshops. Thus only a simple paw is needed. And finally a double-station paw is designed to reduce the time of the hobbing station, which is shown in Fig. 5.

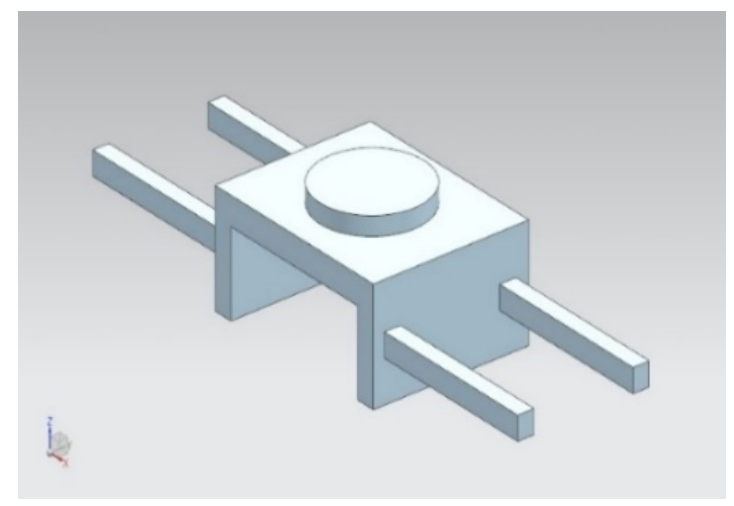

Fig. 5 modeling notation of the double- station paw 
Layout Simulation and Optimization of Production Lines. Linear layout is for narrow space while U-shaped layout applies to workshops of short length and width[9]. Both two ways are not appropriate for the constraints of space in the paper.

There are two other layout ways suitable. Annular layout refers to the layout where the processing equipment is set along an annulus. According to the need of processing technology, works are moved to different facilities along the annulus by the material transportation system. And this kind of layout is widely applied because of its simple structure, easy logistics control and soft materials handling. Island layout, on the other hand, fixes the robot with processing facilities set around it, which is quite compact and saves logistics tempo.

Therefore, these two ways of layout are chosen and compared concretely. Annular layout environment simulation is shown in Fig. 6 and island layout environment simulation in Fig. 7.

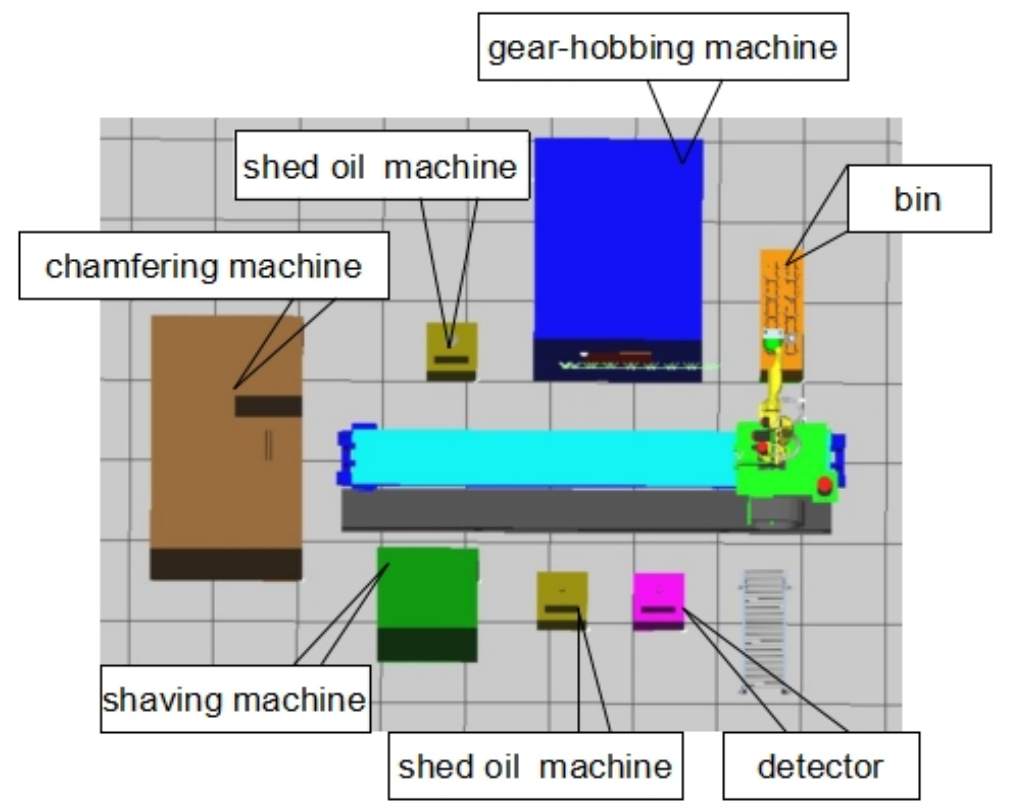

Fig. 6 Annular layout simulation

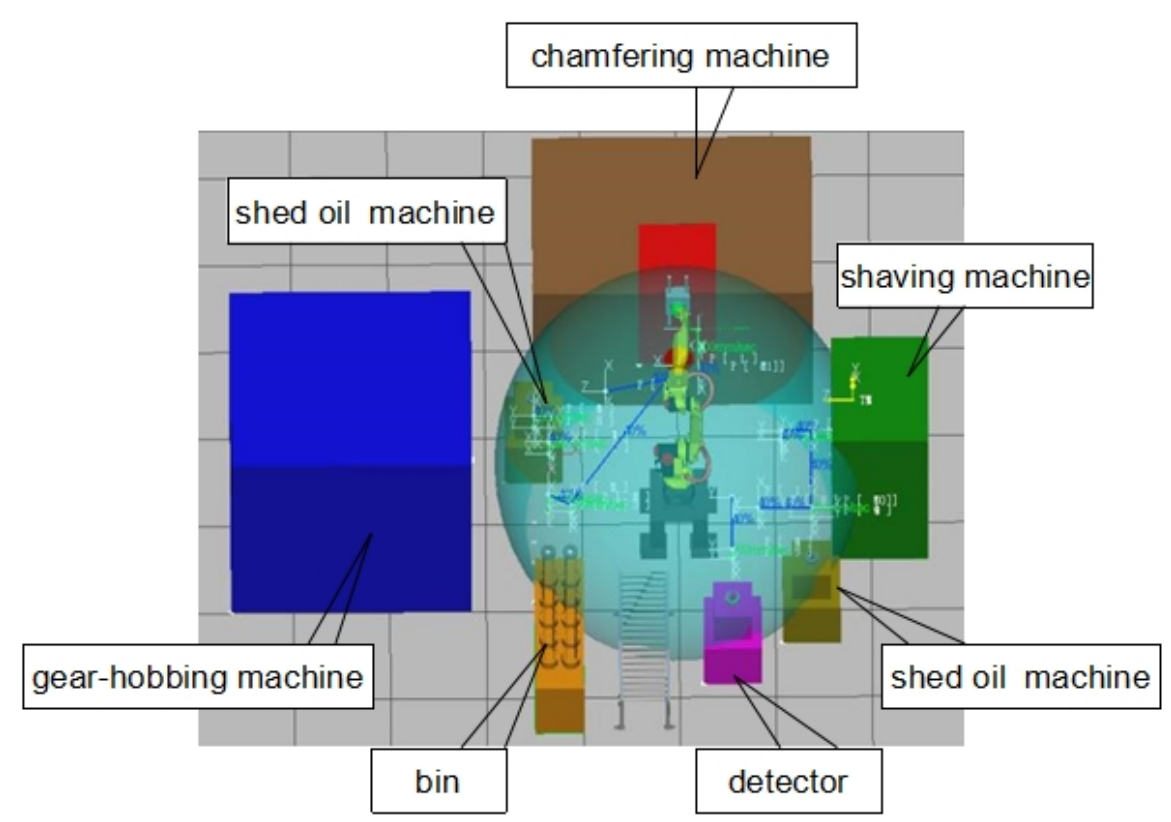

Fig. 7 Island layout simulation 
The result parameters of different layout plans are listed and compared as is shown in Table 3

Table 3 Parameters comparison of results under different equipment layouts

\begin{tabular}{|c|c|c|c|c|c|}
\hline & $\begin{array}{c}\text { Logistics } \\
\text { Rhythm } A_{1}[\mathrm{~s}]\end{array}$ & $\begin{array}{c}\text { Occupied area } A_{2} \\
{\left[\mathrm{~m}^{2}\right]}\end{array}$ & $\begin{array}{c}\text { Minimal Pit lane } \\
A_{3}[\mathrm{~m}]\end{array}$ & $\begin{array}{c}\text { Minimal Foot } \\
\text { Path } A_{4}[\mathrm{~m}]\end{array}$ & $\begin{array}{c}\text { Cost } A_{5} \\
{[¥]}\end{array}$ \\
\hline Annular & 105 & $7.90 \times 6.50$ & 0.80 & 1.20 & 440000 \\
\hline Island & 92 & $7.30 \times 5.60$ & 0.46 & 1.10 & 350000 \\
\hline
\end{tabular}

The simulation results shows that all indexes of both annular and island layouts can satisfy the demands listed in Table 1. The annular layout can ensure the loose layout of overall equipment and reserve adequate pit lanes, but its cost rises because the propel shaft needs incresing and the tempo is intense; the island layout has a narrow structure with rich processing tempo but it is not beneficial for later equipment maintainance, because the arm span of robots is limited and the number of pit lanes narrowly meets the lower demand limit.

To exert quantitative analysis on the functions of both layouts, every single objective is weighted to construct the comprehensive evaluation index of equipment as is shown in Eq. 1.

$$
f=w_{1} \frac{A_{1}}{A_{1}^{*}}+w_{2} \frac{A_{2}}{A_{2}^{*}}+w_{3} \frac{A_{3}}{A_{3}^{*}}+w_{4} \frac{A_{4}}{A_{4}^{*}}+w_{5} \frac{A_{5}}{A_{5}^{*}}
$$

As listed in Table $1, A_{1}{ }^{*}, A_{2}{ }^{*}, A_{3}{ }^{*}, A_{4}{ }^{*}$ and $A_{5}{ }^{*}$ refer to the number of the logistics tempo, the occupied space, the pit lane, the foot path and the cost, respectively. Weights $w_{1}$ to $w_{5}$ for every objectives are used to decide the contribution of them in the comprehensive evaluation index. Here $w_{1}$, $w_{2}, w_{3}, w_{4}$ and $w_{5}$ equal to $0.25,0.15,0.1,0.1$ and 0.4 , respectively. The cost object requires the highest control which the logistics tempo follows. And the pit lane width and the foot path width objects have the lowest weights. $A_{1}, A_{2}, A_{3}, A_{4}$ and $A_{5}$ are the values obtained by layout simulation.

As a smaller floor space, logistics tempo and cost results in bigger advantages while a larger foot path and pit lane interval work better, negative values are made for foot paths and pit lanes during calculating the comprehensive evaluation index. Thus the comprehensive evaluation index of annular and island layouts can be calculated from Eq. 2 and Eq. 3.

$$
\begin{aligned}
& f 1=0.25 \times \frac{105}{110}+0.15 \times \frac{7.9 \times 6.5}{10 \times 10}-0.1 \times \frac{0.8}{0.45}-0.1 \times \frac{1.2}{1}+0.4 \times \frac{440000}{450000}=0.40899 \\
& f 2=0.25 \times \frac{92}{110}+0.15 \times \frac{7.3 \times 5.6}{10 \times 10}-0.1 \times \frac{0.46}{0.45}-0.1 \times \frac{1.1}{1}+0.4 \times \frac{350000}{450000}=0.36930
\end{aligned}
$$

The results are compared under the principle that the smaller index is better, and the island layout appears to be more ideal.

\section{Conclusion}

In order to solve the problem of an automatic production line of gear machining,the paper did a research on processing technology of gears processing lines layout. According to the processing technology of hobbing, chamfering, shaving and the fundamental layout form of processing line, the simulations under annular layout and island-shape layout on specified situation were carried out. The comprehensive evaluation index of layout form was then worked out. After taking cycle time, cost and cover into consideration, the island-shape layout was chose for its better evaluation index. After arranging the equipments with island-shape layout and combining with processing technology, the mutual contents and approaches about robot, machine tool and other peripheral equipments were determined, which can realize the interference judgment of each equipment's movement and achieved 
the automation for whole on-line machining process. The achievement was shown at Fanuc exhibition successfully. To control the quality during auto batches processing, effective on-line measuring and compensating method will be researched future, which will ensure geometric accuracy of gear and guarantee cycle time conformed to the requirement.

Acknowledgment. The research discussed in this paper is supported by Shanghai Science and Technology Commission under Grant No. 13D21101601.

\section{References}

[1] Sophia. "Industry Robot---the Main Force in Metal Processing Automation." Metal Processing 13(2013): 10-13

[2] Jeon,Jaw Wook,Ha,Young Youl. "Generalized approach for the acceleration and deceleration of industrial robots and CNC machine tools." IEEE Transactions on Industrial Electronics 47(1, 2000): 133-139

[3] Hu , Fuwen. "Loading and Unloading manipulator controlled by built-in PLC in CNC system." Sensors \& Transducers 159 ( 11,2013 ) :212-217.

[4] Li Rongli. “ Design of Feeding And Unloading Robot Control System Based on PLC.” Equipment Manufacturing Technology 2(2007): 58-59

[5] Yang T, Peters B A, Tu M. "Layout design for flexible manufacturing systems considering single-loop directional flow patterns. " European Journal of Operational Research 164(2,2005): 440-455.

[6]Drira A, Pierreval H, Hajri-Gabouj S. "Facility Layout Problems: A Survey[J]." Annual Reviews in Control 31(2,2007):255-267.

[7]Liu Shu, Xu Zhipei, Xue Shun, Chen Yongxian. "Mechanical Management And Development as well as Layout Simulation Study of One Manufacturing Company Based on EM-PLANT.” Mechanical Management And Development 05(2009): 35-37

[8]2012,03:25-27. Kang Liutao, Wang Xiaofeng. "Workshop Layout Simulation And Logistics Optimization Based on Digitalized Factory". Mechanical Engineering And Automation 03(2015): $25-27$

[9]Tompkins J A, White J A, Bozer Y A, et al. Facilities Planning[M]. New York: John Wiley \& Sons, Inc., 2003. 